\title{
Investigation of Control Process in Liquid Refrigerant Defrosting System
}

\author{
Meng Wang ${ }^{1}$, Runqing Zang ${ }^{2 *}$, Yanhe $\mathrm{Li}^{3}$, Wenqing $\mathrm{Li}^{4}$ \\ Refrigeration Engineering Research Center of Ministry of Education of People's Republic of China, Tianjin University of \\ Commerce, Tianjin, 300134, (China) \\ E-mail: ${ }^{1}$ wangmeng155@126.com, ${ }^{2}$ zrqing@ tjcu.edu.cn, $\underline{{ }^{3} \text { heerlee@ } 126 . c o m}, \underline{{ }^{4} \mathrm{WqLi} \text { 888@163.com }}$
}

Received 22 June 2018, 20 September 2018, Accepted 24 September 2018

\begin{abstract}
The liquid refrigerant defrosting system (LRDS) has the advantages that the refrigeration process is continuous, the temperature fluctuation of the cold storage is small, and the cooling energy of the frost can be recovered effectively. However, the system is too complex to apply and promote in the modern cold storage. In order to solve the problem of operation difficulty, the control experiments were carried out, including the beginning of the defrosting (BD), the end of the defrosting (ED), the draining time (DT) and the time difference between the two air coolers start-up (TDTACS). The results showed that the LRDS started to defrost when the air pressure difference was higher than $0.5 \mathrm{mbar}$. The outlet should be located at the middle part of the lower $1 / 3$ part of the evaporation surface. The measuring pressure tube inserted the fin $20 \mathrm{~mm}$, and the nozzle was perpendicular to the evaporation pipe. The experimental ambient temperature was $30^{\circ} \mathrm{C}$, and the frost mass was $3 \mathrm{~kg}$. The gas return temperature at the ED was $3.0^{\circ} \mathrm{C}, 4.0^{\circ} \mathrm{C}, 5.0^{\circ} \mathrm{C}, 6.4^{\circ} \mathrm{C}$ and $7.4^{\circ} \mathrm{C}$ respectively when the cold storage temperature was $0^{\circ} \mathrm{C}, 5^{\circ} \mathrm{C}, 10^{\circ} \mathrm{C}, 15^{\circ} \mathrm{C}$ and $20^{\circ} \mathrm{C}$ respectively. The DT was controlled between 140 s and 180 s, which could prevent the wet compression. In order to get the TDTACS, the manual control could be adopted for the first defrosting. Then the air pressure difference control could be used. The two air coolers could refrigerate and defrost alternately.
\end{abstract}

\section{Keywords: Cold storage; defrosting; automatic control; air cooler.}

\section{Introduction}

In the refrigeration system, the air cooler will frost when the surface temperature is below the dew-point temperature and $0^{\circ} \mathrm{C}$. The frost layer on the air cooler surface has the effect of enhancing heat transfer in the initial stage of frosting [1]. However, with the frost layer constant thickening, the heat transfer resistance between the air cooler surface and the surrounding environment will increase. The frost layer will impede the flow of air between the fins, which makes the heat transfer performance of the air cooler worse. Therefore, the COP of the system will reduce [2]. In order to ensure the efficiency of the refrigeration system, periodic defrosting for the air cooler is essential [3]. The commonly used defrosting methods include: hot-gas defrosting [4,5], electric heater defrosting [6, 7], and saltwater defrosting etc.. However, no matter which kind of defrosting method is used, it is necessary to find a suitable start-up time and end time of defrosting. Hence, the research and selection of suitable defrosting control methods are involved.

At present, there are many defrosting control methods. Timing control and timing-temperature control [8] are the most widely used defrosting control methods. Timing control method ensures the BD and ED by time. The timetemperature control method adds the evaporation temperature or superheat temperature as the control signal based on the timing control. The refrigeration system starts to defrost when both the time and temperature conditions are met. The two control methods cost less and have good defrosting effect. J. Xiao, W. Wang and Y. H. Zhao et al. measured the air pressure difference between the air inlet and outlet of the evaporator to determine the BD [9]. When the frost layer increased, the pressure reduction on both sides of the evaporator would increase. Defrosting time could be controlled by the pressure difference. M. H. Kim and K. S. Lee used the effective mass-flow fraction (EMF) method to determine the BD [10]. The method qualitatively detected variation trend of heat transfer rate based on only temperature measurements. Y. Hayashi and A. Aoki et al. studied the formation process of frost by photographic method and predicted thermal conductivity to control defrosting [11]. The control method was basically the same as the photosensor control method in theory. A photoelectric sensor unit consisted of an emitter and a collector. It was installed in the front of outdoor heat exchanger. Accurate defrost control was performed by monitoring and using the change in output voltage according to the presence of frost [12]. However, the two methods are high cost and could not assure the control accuracy. What is more, many other control methods were put forward: reverse cycle defrosting control method [13], the degree of refrigerant superheat defrosting control method [14], ultrasonic defrost control method [15], conduction and radiation heaters defrost control methods [16], adaptive defrost control method [17], refrigerant flow rate control method [18] and temperature-humidity-time defrosting control method [19] etc.. These defrosting control methods have their own advantages and disadvantages. They are suitable for different refrigeration systems and different precision required.

The LRDS uses the liquid refrigerant in high pressure reservoir as heat source to defrost the air cooler. At the time 
of defrosting, the refrigeration cycle does not stop. The liquid refrigerant is undercooled by the frost layer and gets the cold energy, which can improve the efficiency of the refrigeration system and reduce the fluctuation of the cold storage temperature. However, the operation of the system is complex and there is no effective control method, which restricts the popularization and application of the LRDS. Therefore, a lot of experiments were carried out on the system in this paper. According to the research, it was difficult to achieve accurate defrosting control by monitoring only one parameter; it was prone to wrong defrosting. Hence, in the paper, the BD, ED, DT and TDTACS were studied separately. In order to make the LRDS automation, the different control methods were adopted and the different control parameters were monitored.

\section{LRDS Description}

Figure 1 depicts the schematic of the LRDS where the system consists of two air coolers, eight solenoid valve (SV)s, two check valve (CV)s, two thermal expansion valve (TEV)s and a compression condensing unit. The compressor does not stop working when the system is defrosting. In the refrigeration mode, two air coolers are connected in parallel and refrigerate simultaneously. Opening the (1)、(2)、(5) and (6) SVs, the discharge of the compressor passes through the condenser, high-pressure reservoir and filter drier in turn. The refrigerant is divided into two branches: on one branch, it is back to the compressor through the SV (2), TEV, air cooler A and SV (6); on the other branch, it is through the SV (1), TEV, air cooler B and SV (5).

When the air cooler $\mathrm{A}$ is defrosting, the air cooler A turns to the defrosting mode. And the air cooler B is still in the refrigeration mode. The two air coolers are in series. The (4)、(5) and (8) SVs are opened, and the others are closed. The compressed superheated refrigerant changes to the high pressure and medium temperature refrigerant after passing the condenser, high-pressure reservoir and filter drier. Then, the TEV is bypassed, and the refrigerant directly enters into the air cooler A through the SV (4) to defrost. At the time, the air cooler $\mathrm{A}$ is equivalent to a subcooler. Through the SV (8), the $\mathrm{CV}$ and $\mathrm{TEV}$, the subcooling refrigerant flows into the air cooler $\mathrm{B}$ to evaporate and absorb the heat. Finally, it returns to the compressor through the SV (5). When the air cooler B is defrosting, the air cooler B turns to the defrosting mode, and the air cooler $\mathrm{A}$ is still in the refrigeration mode. The two air coolers are also in series. The (3), (6) and (7) SVs are opened, and the others are closed. The specific defrosting process is the same as in the air cooler A.

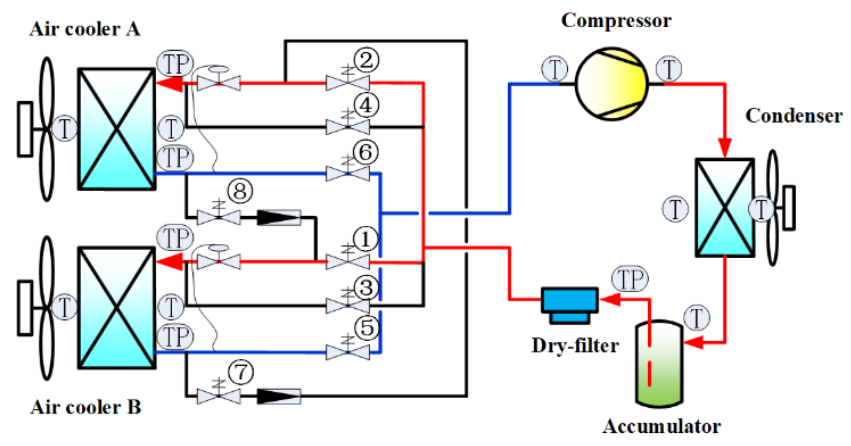

Figure 1. Schematic diagram of the LRDS.

\section{Experimental Approach \\ 3.1 Test rig Description}

In the experiment, the cold storage was an assembly cold storage. The dimension of the body was $2.8(L) \times 2.8$ $(W) \times 2.5(H) \mathrm{m}$. The thermal insulation material selected the rigid polyurethane foam with the thickness of $100 \mathrm{~mm}$. The schematic diagram of the air cooler was shown in Figure 2, where the outlet of the air cooler set the shutter. There also are air pressure difference controllers on it. The detailed information of the LRDS was shown in Table 1. The working fluid of the system was R22.

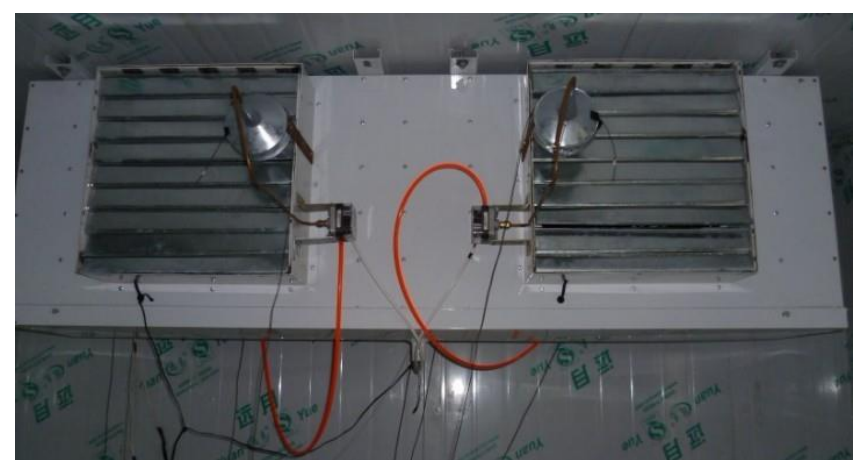

Figure 2. Schematic diagram of the air cooler with air pressure difference controllers.

Table 1. Specifications of the device.

\begin{tabular}{lll}
\hline Item & Parameters & Values \\
\hline Compressor & Type & Piston compressor \\
& Displacement & $22.6 \mathrm{~m}^{3} / \mathrm{h}$ \\
Condenser & Type & Air-cooled condenser \\
& Air volume & $4800 \mathrm{~m}^{3} / \mathrm{h}$ \\
High-pressure & Volume & $6 \mathrm{dm}^{3}$ \\
reservoir & Heat exchanger area & $38 \mathrm{~m}^{2}$ \\
Air cooler & Evaporator pipe & $12 \mathrm{~mm}$ \\
& diameter & $6 \mathrm{~mm}$ \\
& Fin spacing & $270 \mathrm{~W}$ \\
& Fan power & EVR2-40 \\
SV $\times 8$ & Type & TEX2 \\
TEV $\times 2$ & Type & $15 \mathrm{~kW}$ \\
Electric heater & Maximum power & $200 \mathrm{~W}$ \\
& Fan power & $6 \mathrm{~kg} / \mathrm{h}$ \\
\hline
\end{tabular}

\subsection{Data Acquisition System}

The LRDS arranged 18 temperature measurement points and 5 pressure measurement points. The placement positions were shown in Figure 1, where " $\mathrm{T}$ " represented temperature measurement points, and "TP" represented temperature and pressure measurement points. The $\mathrm{T}$ type thermocouple was used for the temperature measurement and the error was $\pm 0.3^{\circ} \mathrm{C}$. The type of the pressure transmitter was HM23-1-A1-F1-W1. The measurement error of the pressure transmitter over the effective measurement range of $0 \sim 2.5 \mathrm{MPa}$ was $\pm 0.01 \mathrm{Mpa}$. The compressor power was measured by a three-phase power meter. The MX100 multipoint parameters recorder automatically saved the data which was scanned consecutively in every $1 \mathrm{~s}$.

\subsection{Experimental Procedure}

The experimental conditions were as following: the experimental ambient temperature was $30^{\circ} \mathrm{C}$; the cold storage temperature was $0^{\circ} \mathrm{C}, 5^{\circ} \mathrm{C}, 10^{\circ} \mathrm{C}, 15^{\circ} \mathrm{C}$ and $20^{\circ} \mathrm{C}$ respectively; the full frost on the air cooler was shown in Figure 3(2), where the frost mass was approximately $3 \mathrm{~kg}$. 
In the refrigeration condition, the (1), (2), (5) and (6) SVs were opened, and the (3), (4), (7), (8) SVs were closed. The humidifier was turned on to humidify the cold storage slowly when the cold storage temperature reached to the set temperature stably. The system started to defrost when the air pressure difference is higher than $0.5 \mathrm{mbar}$, and the frost situation should be observed. The refrigeration system would run an hour stably after the humidification. Then the (2), (5) and (8) SVs were opened, and the others were closed. The air cooler A started to defrost. The gas return temperature of the air cooler was recorded when there was no frost on the surface of the air cooler, which was shown in Figure 3(1). The (1), (2), (5) and (6) SVs were opened, and the other SVs were closed when the defrosting was over, and the air coolers restarted to refrigerate in parallel. At the time, the opening time of the (2) SV was controlled by the time relay. As for the experiment of the SV start-up delay, the delay time was increased to 200 s, taking 10 s as the step length. By observing the frosting condition of the suction inlet of the compressor, there is no severe frost, which makes no moisture gas return phenomenon occur and controls the temperature fluctuation of the cold storage within $5^{\circ} \mathrm{C}$. When the cold storage temperature stabilized to the set temperature, the (3), (6) and (7) SVs were opened, and the other SVs were closed. The LRDS switched to defrost for the air cooler B.
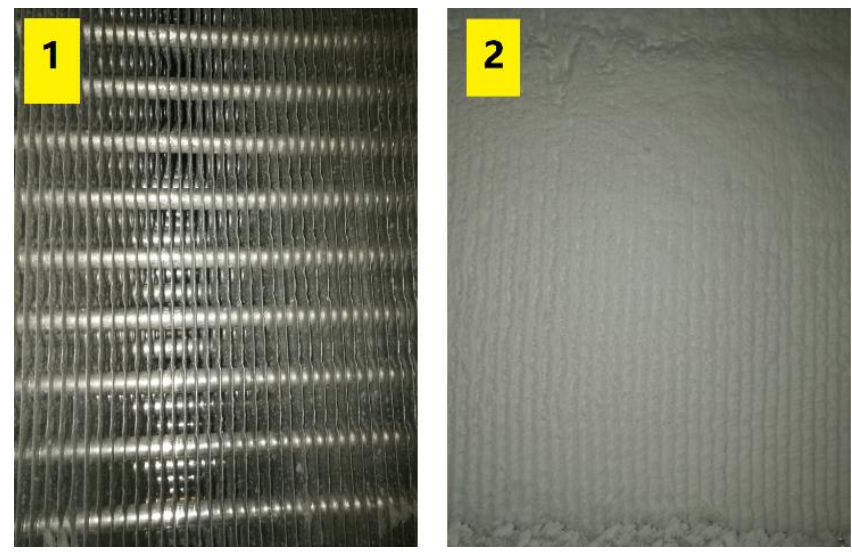

Figure 3. Contrast diagram of air cooler before and after frosting (1-before frost, 2-full frost).

\section{Results and discussion \\ 4.1 BD control}

The LRDS used the air pressure difference control method to control the BD. The air pressure difference control system was shown in Figure 4. The measurement range of the air pressure difference controller was 0.20 2.00 mbar (error was $0.01 \mathrm{mbar}$ ). The controller had two pressure guide interfaces, one for import and the other for export. The inlet nozzle faced the fan of the air cooler and connected the outlet tube through the pressure tube, and the outlet tube was inserted into the air return surface of the air cooler. The installation position and method of inlet and outlet air pressure difference controller would directly affect the accuracy of control. In this paper, reasonable installation position was obtained by experiments. The connection between inlet nozzle and pressure tube should be tightly sealed avoiding air leakage. The area of the windward side should be expanded. And the windward side should face the outlet of the fan to ensure the smooth entry of wind. The outlet should be located at the middle part of the lower $1 / 3$ part of the evaporation surface, which excludes the influence of backflow on wind pressure measurement caused by air return cover. The air coolers were equipped with axial fans. The diameter of the fan was $400 \mathrm{~mm}$. The air volume was $3400 \mathrm{~m}^{3} / \mathrm{h}$, and the fan power was $180 \mathrm{~W}$. The running fan should overcome the pressure drop of the evaporation tube group. The air pressure at the air return inlet was almost 0 mbar. Therefore, the pressure tube should be inserted into the fin $20 \mathrm{~mm}$ so that the outlet pressure of the air pressure difference controller was higher than 0 mbar when the air cooler has no frost. The inlet nozzle should be perpendicular to the evaporation tube.

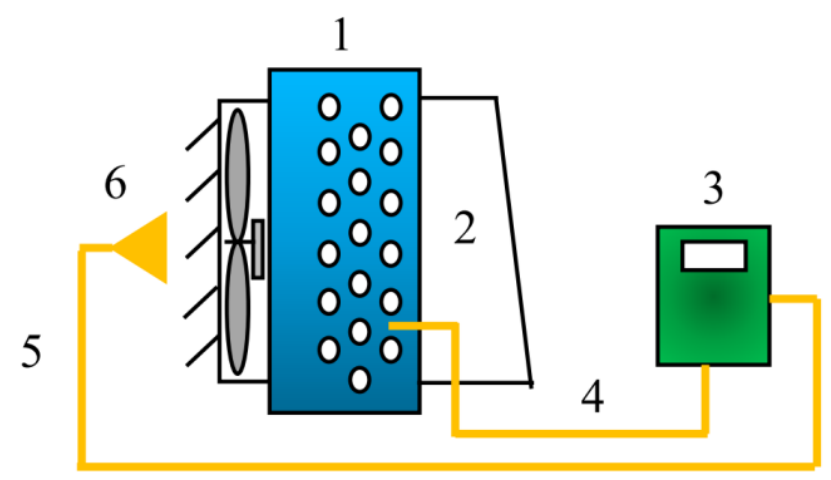

Figure 4. Schematic diagram of the air pressure difference controller (1-air cooler, 2-air return cover, 3-air pressure difference controller, 4- outlet tube, 5- pressure tube, 6inlet nozzle).

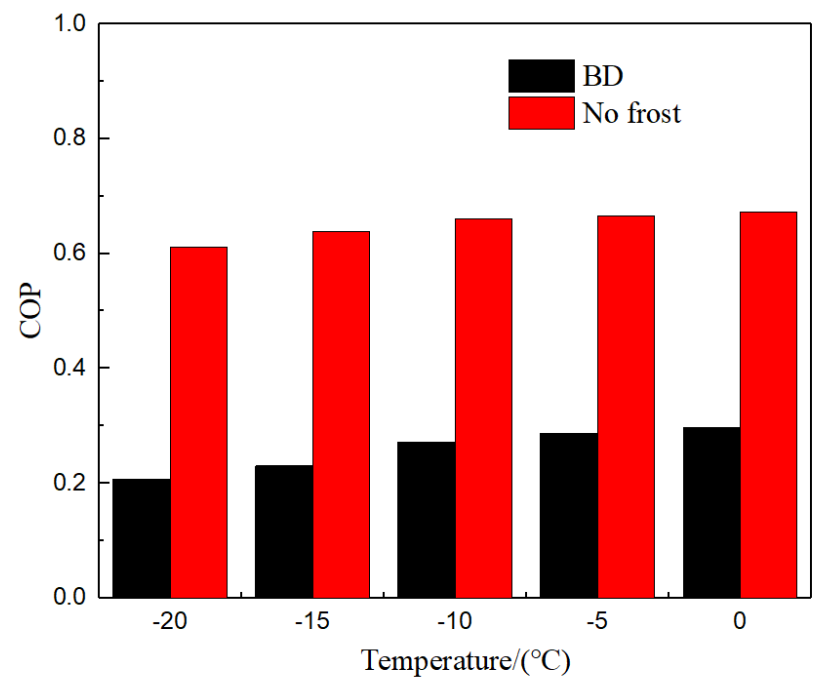

Figure 5. Variety of COP with the cold storage temperature

According to the above installation position, the air pressure difference controller could accurately control the BD. The experiments found that when the air pressure difference was higher than $0.5 \mathrm{mbar}$, the LRDS started to defrost. At the time, the fin surface was completely frosted, and the frost mass was approximately $3 \mathrm{~kg}$. As is shown in Figure 5, the COP of the LRDS changes with the storage temperature at the $\mathrm{BD}$ and no frost. The $\mathrm{BD}$ signal in the figure used the above control method. The results showed that the air cooler had been completely frosted at the BD. The channel between the fin was blocked, and the air cannot circulate. Therefore, the refrigeration capacity was greatly reduced. At the same time, the evaporation temperature was dropped, and the power consumption was increased. The running resistance of the axial fan was increased, which also led to increase in power consumption. 
The positive difference of refrigeration capacity and the negative difference of power consumption made the variation of COP (about 0.4 ) very significant. In addition, the higher the cold storage temperature, the higher the COP. However, under different cold storage temperature conditions, the difference of COP was basically the same, which shows that the BD control was accurate.

\subsection{ED control}

During defrosting, the part of the air coolers would be frozen and hard to defrost. Most of these parts located at the bottom of the air coolers where the air pressure difference controllers are placed, so that the gas pressure difference control method was not good enough. In this paper, the gas return temperature of the defrosting evaporator was used as the trigger signal for the ED control. Theoretically, the temperature of the entire evaporator coil would be above the freezing point when the gas return temperature was higher than $0^{\circ} \mathrm{C}$, and the defrosting was complete. However, as shown in Figure 6(1), there was still some residual frost between the fins when the gas return temperature was $0^{\circ} \mathrm{C}$. This was because the high pressure medium temperature liquid refrigerant flowed in the tube. The heat was transmitted to the fin after the evaporation tube was heated. The heat resistance was large, and a higher gas return temperature was required to defrost. In addition, the LRDS was cooling and defrosting at the same time. The heated evaporation tube group were at a lower temperature of the cold storage and needed to counteract the cooling effect. The end of the fin was more strongly cooled by the air in the cold storage, so that the frost of the end was hard to melt. Therefore, the gas return temperature must be higher than $0^{\circ} \mathrm{C}$ to ensure complete defrosting, and the specific value needed to be measured by experiments. The Figure 6(2) showed that the defrosting of the air cooler was completed when the cold storage temperature was $-20^{\circ} \mathrm{C}$ and the gas return temperature was $7.2^{\circ} \mathrm{C}$. The initial frost mass was $3 \mathrm{~kg}$, and the gas return temperatures of the defrosting air cooler at the ED were measured in the different cold storage temperatures, shown in Table 2. Different cold storage temperatures had a great influence on the gas return temperature at the ED. The lower the cold storage temperature, the higher the gas return temperature needed after defrosting.
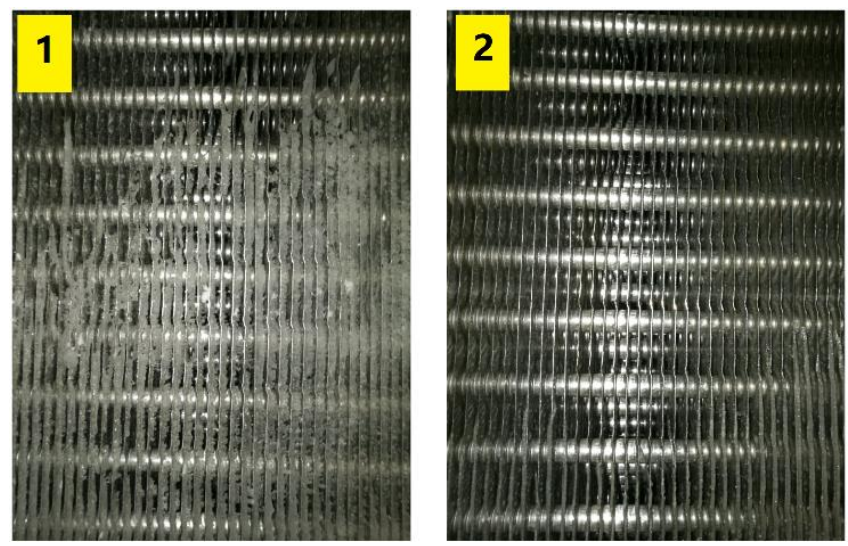

Figure 6. Schematic diagram of the air cooler with the cold storage temperature $-20^{\circ} \mathrm{C}$ (1-gas return temperature was 0 ${ }^{\circ} \mathrm{C}$, 2- gas return temperature was $7.2^{\circ} \mathrm{C}$ )

In addition, the load in the cold storage during the experiment included a fan of $360 \mathrm{~W}$, a lighting equipment of
$80 \mathrm{~W}$, and the heat input through the maintenance structure. All the load was shown in Table 2. In the five working conditions of the defrosting process, the higher the cold storage temperature, the smaller the rise value of the cold storage temperature. Even to the extent that there might be a decrease in the cold storage temperature instead of increasing in the working condition of $0^{\circ} \mathrm{C}$. During the defrosting process, although the evaporation area was reduced by half and the cooling capacity was reduced, the refrigerant improved the sub-cooling of the LRDS by recovering the cooling of the frost. And the cooling capacity was compensated. The higher the cold storage temperature, the higher the evaporation temperature. The system had more refrigeration capacity. Moreover, the higher the cold storage temperature, the lower the cooling leakage was observed. The load in the cold storage was small. Synthesis of the above factors, the higher the cold storage temperature, the lower the increasing value of cold storage temperature during the defrosting. The Figure 7 shows that the changes of the cold storage temperature during defrosting with the cold storage temperature set $20^{\circ} \mathrm{C}$ at the beginning. The sub-cooling of the $\mathrm{AB}$ segment was high so that the cold storage temperature decreased first. During the defrosting, the sub-cooling gradually decreased, and the cold storage temperature gradually increased. Approaching the ED, the rate of the cold storage temperature increased. The increase rate of $\mathrm{CD}$ segment was obviously higher than BC segment.

Table 2. ED values at different cold storage temperature

\begin{tabular}{llllll}
\hline $\begin{array}{l}\text { Temperature } \\
\left({ }^{\circ} \mathrm{C}\right)\end{array}$ & -20 & -15 & -10 & -5 & 0 \\
\hline $\begin{array}{l}\text { Gas return } \\
\text { temperature } \\
\left({ }^{\circ} \mathrm{C}\right)\end{array}$ & 7.2 & 6.4 & 5.0 & 4.0 & 3.0 \\
$\begin{array}{l}\text { Thermal } \\
\text { load }(\mathrm{W})\end{array}$ & 633.1 & 603.3 & 585.9 & 564.4 & 543.0 \\
$\begin{array}{l}\text { Increased } \\
\text { value of the } \\
\text { cold storage } \\
\text { temperature } \\
\left({ }^{\circ} \mathrm{C}\right)\end{array}$ & 5.2 & 2.7 & 1.8 & 1.0 & -0.5 \\
\hline
\end{tabular}

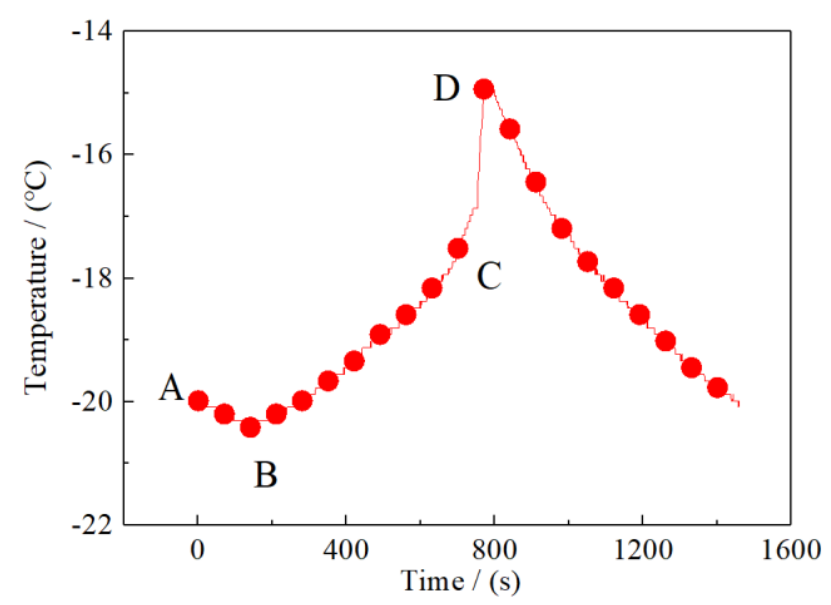

Figure 7. Variety curve of cold storage temperature in defrosting process with the cold storage temperature $-20^{\circ} \mathrm{C}$

It was worthy to point that the LRDS used the high pressure liquid produced by the refrigeration cycle to defrost. The compressor should not stop working during defrosting. If the storage temperature was too high, the refrigeration capacity of the system would be higher than the heat load in the cold storage. At the time, the 
compressor would be restrained by the temperature controller. The compressor would be stopped to ensure that the cold storage temperature fluctuated within a certain range. Therefore, as for the cold storage of the small heat load, the temperature controller should be locked during defrosting, which prevented the compressor from shutting down if the cold storage temperature continued to decrease. In this way, the compressor could be opened all the time.

\subsection{DT control}

The defrosting air cooler was filled with high pressure liquid refrigerant at the ED. If the system recovered the refrigeration mode at once, the TEV would sense the high temperature of the gas return pipe and increase the opening. A large amount of liquid refrigerant was injected into the compressor, resulting in wet compression. As shown in Figure 8, a large area of frost appeared near the suction of the compressor, which damaged the compressor severely. Therefore, the SV of the gas return should be opened first after defrosting. When the liquid refrigerant was evaporated in the air cooler, the SV of the liquid supply was opened The DT (the delay opening time of the SV of the liquid supply) needed to be tested by experiment. If the DT was too short, the compressor would frost severely. But if the DT was too long, the cold storage temperature would fluctuate. Under the different working conditions, the temperature and pressure of the liquid refrigerant filled in the air cooler was almost the same at the ED. Therefore, the DT was basically not affected by the operating conditions. Finally, the experimental results showed that the DT was appropriate for 140 s to $180 \mathrm{~s}$. The suitable DT could not only avoid the wet compression, but also improve the operating efficiency of the LRDS with the time of the second cooling was shorted.

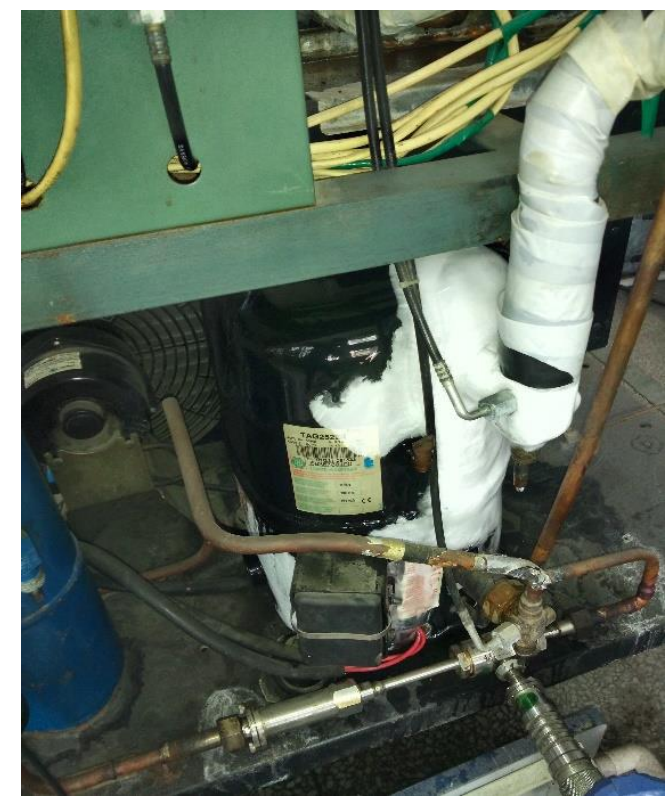

Figure 8. Schematic diagram of the wet compression

\subsection{TDTACS control}

In addition to the above process needing to be controlled, the LRDS had a special feature of alternately defrosting of two air coolers. Theoretically speaking, the two air coolers in the same temperature and humidity environment had the same frost mass when the operating period were the same. If the control value of the air pressure difference controller was set the same, the two air coolers would defrost at the same time with the high and low pressure of the LRDS being erratic. Therefore, some control measures should be taken to prevent this phenomenon from happening.

There were two specific control measures: the first one was that when the system was started-up, one air cooler was put into operation first and then the other after a period of delay; the second measure adopted was the first defrosting process was a manually controlled. After the two air coolers finished once alternately cooling and defrosting, the time difference on the cooling operation naturally occurred. Then the air pressure difference control method was used to defrost in the next operation. The experimental results showed that the first kind of control method had only one cooling air cooler in the initial stage of the refrigeration, and there was no sub-cooling to compensate the system. The evaporation area reduced a half, so the suction pressure of the refrigeration system reduced to about $0.1 \mathrm{MPa}$ (Absolute pressure), and the corresponding evaporation temperature was about $-40^{\circ} \mathrm{C}$. At this time, the cold storage temperature was $-20^{\circ} \mathrm{C}$. The heat transfer temperature difference was $20^{\circ} \mathrm{C}$, increased by $10^{\circ} \mathrm{C}$. The efficiency of refrigeration system was obviously reduced. The second control method was more economical, but it required manual operation.

In fact, it was also feasible to realize second schemes by means of automatic control. The main design principles were that the system entered the initial control section when the compressor was started. The air pressure difference control method was invalid, and the timing as the trigger signal for defrosting (timing control priority). After the first alternately cooling and defrosting, the defrosting trigger signal was switched to air pressure difference control (air pressure difference control priority). This experimental scheme is to be verified in future experiments.

\section{Conclusions}

The automatic control experiments were carried out at the following conditions: the experimental ambient temperature was $30^{\circ} \mathrm{C}$; the cold storage temperature was $0^{\circ} \mathrm{C}, 5^{\circ} \mathrm{C}, 10^{\circ} \mathrm{C}, 15^{\circ} \mathrm{C}$ and $20^{\circ} \mathrm{C}$ respectively; the frost mass was approximately $3 \mathrm{~kg}$. The following conclusions could be drawn:

- The air pressure difference control system was used at the BD. The LRDS started to defrost when the air pressure difference was higher than $0.5 \mathrm{mbar}$. The connection between inlet nozzle and pressure tube should be tightly sealed avoiding air leakage. The area of the windward side should be expanded. And the windward side should be expanded with the windward side facing the outlet of the fan. The outlet should be located at the middle part of the lower $1 / 3$ part of the evaporation surface. The measuring pressure tube inserted in the fin at $20 \mathrm{~mm}$, and the nozzle perpendicular to the evaporation pipe.

- The gas return temperature was used as the trigger signal for the ED. The gas return temperature at the ED was affected by the factors such as the cold storage temperature, air flow rate and whether the air coolers were closed, so that it could only be determined by experiment. The results showed that the gas return temperature was $3.0^{\circ} \mathrm{C}, 4.0^{\circ} \mathrm{C}, 5.0^{\circ} \mathrm{C}, 6.4^{\circ} \mathrm{C}$ and $7.4^{\circ} \mathrm{C}$ respectively when the cold storage temperature was $0^{\circ} \mathrm{C}, 5^{\circ} \mathrm{C}, 10^{\circ} \mathrm{C}, 15^{\circ} \mathrm{C}$ and $20^{\circ} \mathrm{C}$ respectively.

- The DT (the delay opening time of the SV of the liquid supply) was appropriate for 140 s to 180 s, which 
could not only avoid the wet compression, but also improve the operating efficiency of the LRDS, with the time of the second cooling shortened.

- The LRDS used the alternately defrosting method of two air coolers. The frost thickness of the two air coolers were the same at the beginning, which could lead to the derangement of the defrosting control process. Therefore, the TDTACS should be controlled. At present, the first defrosting process adopted a manual control method. After two air coolers finished alternately cooling and defrosting, the air pressure difference control method would be used to defrost in the next operation. However, this method required manual operation. It was better to use the time - air pressure difference joint control method which are to be verified in future experiments.

\section{Acknowledgements:}

It is gratefully acknowledged that this work is sponsored by the Tianjin City High School Science \& Technology Fund Planning Project [2016ZT010607].

\section{References:}

[1] P. Byrne, J. Miriel, Y. Lenat, "Experimental study of an air-source heat pump for simultaneous heating and cooling - Part 2: Dynamic behaviour and two-phase thermosiphon defrosting technique," Appl. Energy, 88, 3072-3078, 2011.

[2] W. J. Hu, Y. Q. Jiang, M. L. Qu, L. Ni, Y. Yao, S. M. Deng, "An experimental study on the operating performance of a novel reverse-cycle hot gas defrosting method for air source heat pumps," Appl. Therm. Eng., 31, 363-369, 2011.

[3] M. L. Qu, L. Xia, S. M. Deng, Y. Q. Jiang, "A study of the reverse cycle defrosting performance on a multicircuit outdoor coil unit in an air source heat pump Part I: Experiments,” Appl. Energy, 91, 122-129, 2012.

[4] Z. Y. Wang, H. X. Yang, S. Chen, "Study on the operating performance of cross hot-gas bypass defrosting system for air-to-water screw heat pumps," Appl. Therm. Eng., 59, 398-404, 2013.

[5] N. Hoffenbecker, S. A. Klein, D. T. Reindl, "Hot gas defrost model development and validation," Int. J. Refrig., 28, 605-615, 2005.

[6] H. J. Yin, Z. Yang, A. Q. Chen, N. Zhang, "Experimental research on a novel cold storage defrost method based on air bypass circulation and electric heater," Energy, 37, 623-631, 2012.

[7] K. Kwak, C. Bai, "A study on the performance enhancement of heat pump using electric heater under the frosting condition: Heat pump under frosting condition," Appl. Therm. Eng., 30, 539-543, 2010.
[8] S. A. Tassou, D. Datta, D. Marriott, "Frost formation and defrost control parameters for open multideck refrigerated food display cabinets," Proceedings of the Institution of Mechanical Engineers Part A Journal of Power \& Energy, 215, 213-222, 2001.

[9] J. Xiao, W. Wang, Y. H. Zhao, F. R. Zhang, “An analysis of the feasibility and characteristics of photoelectric technique applied in defrost-control," Int. J. Refrig., 32, 1350-1357, 2009.

[10] M. H. Kim, K. S. Lee, "Determination method of defrosting start-time based on temperature measurements," Appl. Energy, 146, 263-269, 2015.

[11] Y. Hayashi, A. Aoki, S. Adachi, K. Hori, "Study of frost properties correlating with frost formation types," J. Heat Transfer, 99, 239, 1977.

[12] Y. J. Ge, Y. Y. Sun, W. Wang, J. H. Zhu, L. T. Li, J. D. Liu, "Field test study of a novel defrosting control method for air-source heat pumps by applying tube encircled photoelectric sensors," Int. J. Refrig., 66, 133144, 2016.

[13] M. J. Song, X. J. Wang, L. Y. Liao, S. M. Deng, "Termination Control Temperature Study for an Air Source Heat Pump Unit During Its Reverse Cycle Defrosting," Energy Procedia, 105, 335-342, 2017.

[14] Y. Q. Jiang, J. K. Dong, M. L. Qu, S. M. Deng, Y. Yao, "A novel defrosting control method based on the degree of refrigerant superheat for air source heat pumps," Int. J. Refrig., 36, 2278-2288, 2013.

[15] H. H. Tan, G. H. Xu, F. T. Tao, X. Q. Sun, W. D. Yao, "Experimental investigation on the defrosting performance of a finned-tube evaporator using intermittent ultrasonic vibration," Appl. Energy, 158, 220-232, 2015.

[16] Y. C. Yoon, H. J. Jeong, K. S. Lee, “Adaptive defrost methods for improving defrosting efficiency of household refrigerator," Energy Conversion \& Management, 157, 511-516, 2018.

[17] J. Allard, R. Heinzen, "Adaptive defrost," IEEE Transactions on Industry Applications, 24, 39-42, 1988.

[18] Z. Y. Wang, X. M. Wang, Z. M. Dong, "Defrost improvement by heat pump refrigerant charge compensating," Appl. Energy, 85, 1050-1059, 2008.

[19] J. H. Zhu, Y. Y. Sun, W. Wang, Y. J. Ge, L. T. Li, J. D. Liu, "A novel Temperature-Humidity-Time defrosting control method based on a frosting map for air-source heat pumps," Intern. J. Refrig., 54, 45-54, 2015. 